\title{
Growing Corns by Grain-Growing Technology in Siberia
}

\author{
Evgeniy Demin \\ Department of Soil Sciences and Agrochemistry \\ Federal State Budgetary Educational \\ Institution of Higher Education \\ «Northern Trans-Ural State Agricultural University» \\ Tyumen, Russia \\ gambitn2013@yandex.ru
}

\author{
Dmitry Eremin \\ Istitute of Agrotechnologies \\ Federal State Budgetary Educational \\ Institution of Higher Education \\ «Northern Trans-Ural State Agricultural University» \\ Tyumen, Russia \\ soil-tyumen@yandex.ru
}

\begin{abstract}
The development of animal husbandry in Siberia has led to the necessity to form stable fodder base at the expense of domestic products. Many producers and scientists consider the corn as the most promising culture. It is the integral component at the creation of a high-energy forage for farm animals and birds. High content of nutrient elements in corn kernels and the content of nonreplaceable amino acids turn this culture into a main element in feeding animals. The aim of the research is to study the producing corn kernels in the foreststeppe zone of the Trans-Ural region. The investigations were carried out in the leached loamy black earth area with characteristic morphological features and properties for soils in the South of the Tyumen region. The scheme of the experiment included two sowing dates on May 15 and on May 25, and options with various level of feeding for planned yield 4.0; 5.0 and 6.0 t/ha of corn kernels. In the experiment the hybrid Ladozhskyi 148 was sowed (FAO 150). The vegetation period of corn at sowing on May 15 was 132-137 full days, shifting the sowing date to the 3rd decade of May has provided the reduction of this period by 6-7 full days. Its greatest gain was observed at a milk stage of corn kernels where it was 11,05$16,49 \mathrm{t} / \mathrm{ha}$. Shifting the sowing date into the 3rd decade of May has increased this indicator by $22-31 \%$. Seeding crops on May 15 allowed to obtain the planned yield in all options. When seeding crops on May 25 there was a decrease in yield by 14$24 \%$ in comparison with the first term. Harvest humidity of corn kernels at the first sowing date was 34.4-34.8\% of weight. The disbalance of feeding elements in variant with the planned yield of $5.0 \mathrm{t} / \mathrm{ha}$ of corn kernels has led to increasing humidity up to $38.9 \%$. Shifting sowing date to the third decade of May has increased the indicator by $\mathbf{1 . 9 - 4 . 0 \%}$ in regards to the first sowing date.
\end{abstract}

Keywords - corn, mineral fertilizers, the vegetative period, corn biomass, yield.

\section{INTRODUCTION}

Successful development of animal husbandry production in regions of Russia demands the creations of a stable fodder base at the expense of local production. The opportunity to cultivate corn on grains has interested the Siberian producers who are engaged in pig-breeding and poultry farming. A particular interest in this culture is not casual, as the kernels of this culture is an important component of high-energy compound feeds suitable for feeding all farm animals and birds. The main advantage of corn kernels is that it contains a large number of minerals, vitamins, carbohydrates and nonreplaceable amino acids which help animals to gain weight and fully developed. As a part of compound feeds the proportion of corn kernels is about $50-60 \%$ of total weight. Such high share of this component in feeds is explained by its good digestibility which reaches $90 \%$ and with a high forage value of 1.34 fodder units. Corn surpasses the most part of the grain crops growing up in Siberia and even oats, containing up to $257 \mathrm{kcal} / 100 \mathrm{~g}[1-4,16]$ in the content of exchange energy. However, despite the mass of positive indicators, in mixed feed formula for feeding birds in Russia the proportion of corn gradually decreases, conceding to wheat, oats, barley. The main reason for it is the lack of local grains in regions with severe climate and the high cost of imported grains. This problem is particularly topical for Siberia where the animal husbandry production actively develops, and corn kernels should be bought and brought from other regions [3-5]. It significantly influences an economic situation in the animal husbandry enterprises and the cost of meat production.

The adverse and severe climate of Siberia is one of the decisive factors interferring the cultivation of corn on grain in this region, as well as rather short summer - about 120 full days. Frequent late spring and early autumn frosts, the low sum of effective and active temperatures limited the advance of growing corn on grain in the northern regions of the country until recently.

Optimum temperature range for corn growing ranges within 12 and $25^{\circ} \mathrm{C}$, the optimum daytime air temperature is $22-25{ }^{\circ} \mathrm{C}$, with night decrease is no more than $16-18{ }^{\circ} \mathrm{C}$. Depending on the stage of development the corn needs different air temperature. For emergence of good sprouts the optimum temperature should be $15-18{ }^{\circ} \mathrm{C}$. A biological minimum is quite high in comparison with the usual grain crops: $10-12{ }^{\circ} \mathrm{C}$, that is twice higher than indicators for summer wheat, oats and barley. To form generative bodies the optimum temperature condition ranges from 16 to $20^{\circ} \mathrm{C}$, however, the biological minimum for emergence of generative bodies is within $12-15^{\circ} \mathrm{C}$. Maturing of grain flows at the temperature of $10-12{ }^{\circ} \mathrm{C}$, increasing average daily air temperature till $18-24{ }^{\circ} \mathrm{C}$ considerably reduces the term of corn kernel maturing.

The influence of the temperature factor on the growth and development of corn has been quite well studied. Sprouting of corn is possible at the soil temperature of $8-10^{\circ} \mathrm{C}$. It is claimed that at the minimum soil temperatures the preemergent period is dragged, that can negatively affect field emergence, and, finally, will reduce the yield of culture. Corn sprouts are capable to endure single morning frosts from $-2^{\circ}$ to $-4{ }^{\circ} \mathrm{C}$, at lower temperatures corn dies out. In the Siberian zone the last spring frost is on May 26-27. Frosts of such intensity (to- $4^{\circ} \mathrm{C}$ ) are noted only in the first decade of May or later in the territory with a negative element of terrain. Emergence of corn sprouts usually happens in 10-12 days 
after seeding. Therefore, seeding corn at the beginning of the second decade of May significantly reduces the risk of damaging sprouts. It is also better to choose the fields for corn cultivation in heights preferably in the southern or southwest exposition. This will considerably reduce the probability of corn death after autumn frosts which happen in the third decade of September in the forest-steppe zone of the Tyumen region. Usually these frosts happen in lowlands whereas in the highlands the minimum air temperature remains positive during this period.

For many years this culture in Siberia has been grown up for silage, using late-season hybrids FAO 300 and more. Use of such hybrids led to obtaining a large number of herbage, however, no more than $10 \%$ of total weight was milky stage corn, and the nutrient value of this forage was rather low. The productivity of dairy animals from feeding by such forage was low as well. Therefore, to improve nutritiousness of succulent fodder, the task of inventing early-season hybrids was set before the selectionists. Successful development of modern selection, supported by engineering biotechnology, the emergence of molecular and genetic laboratories have developed many crop varieties, including early season corn hybrids which, in the experience, are capable to mature even in the conditions of Siberia [6-8].

Special focus should be paid to feeding this culture at cultivation stage in the Northern Trans-Ural region, as the soils in the forest-steppe zone of the Trans-Ural region is mainly cold, heavy with low aeration, that complicates the consumption of essential nutrients $[9,10]$.

Corn is a very exacting culture in relation to nutrients. It is connected with high intensity of biochemical reactions in it and growth processes, and also with the formation of big vegetative weight. At the beginning of vegetation it acquires nutrients very badly because of underdeveloped root system as well as owing to low positive temperatures of an arable layer. And only by the beginning of blossoming there is an intensive absorption of nutrients from the soil. The root system of early season hybrids always concedes to lateseason corn. In this regard it acquires nutrients and water from all root habitable layer [13] better.

Absorption of nutrients takes place throughout the whole period of corn growth, however, the maximum speed of absorption is noted at heading of panicles stage - blossoming. Corn consumption of nutrients depends on air temperature, soil, and rainfalls. Moreover, the intensity of absorption of nutrients is a biological feature of hybrids and their interaction with various types of soils.

The maximum necessity for nitrogen comes at the heading stage - during this period corn acquires up to $40 \%$ whereas in earlier phase - no more than $4 \%$ of the necessary wants for nutrients. The high efficiency of nitrogen fertilizers during inter-row cultivations is also explained by it. In the conditions of a forest-steppe zone of the Trans-Ural region there is a probability of nitrogen fertilizers removal at the beginning of vegetation. Therefore, it is better to bring them in the form of top dressing [14-16]. Perhaps, for rational use of nitrogen fertilizers not only the use of ammonium nitrate is possible, but also the encapsulated urea which provides plants with nutrients in later terms of development (blossoming milky stage) owing to slow-release action. The termination of nitrogen intake happens at wax stage.

During formation of future inflorescence, corn needs phosphorus much, the lack of this element leads to the underdevelopment of earcorns that negatively affects the productivity. In Siberian conditions corn at early stages of the development cannot absorb phosphorus fully by its root system, even with feeding by corresponding fertilizers, because of the low temperature of an arable layer which is not exceeding $10^{\circ} \mathrm{C}[17]$.

Besides positive influence on generative bodies, phosphorus has the stimulating effect on the development of corn root system that favorably affects the consumption of nitrogen, potassium and especially minerals at later stages of development. It promotes fast formation of full-fledged ears and accelerates grain maturing. Corn consumes phosphorus several times less, than nitrogen and potassium, the assimilation happens evenly equable during all vegetation [18].

Phosphoric fertilizers are slowly dissolved, therefore, it is better to bring them after cleaning of the predecessor. It is necessary to remember that corn will not be able to use them fully during an initial stage of vegetation, thus it is necessary to provide extra root treatment.

Potassium plays an essential role in development of corn. The lack of this element slows down the movement of carbohydrates, reduces photosynthetic activity of leaves and leads to weakening root system. It comes to a plant during the entire period of vegetation, the maximum requirement happens at heading of panicles stage and is $65 \%$ of the general removal. Considering that potassium is not washed from the soil it is better to bring it in autumn underwinter plowing [19].

The aim of the research: receiving the planned corn kernel yield by means of introducing mineral fertilizers in the forest-steppe zone of the Trans-Ural region.

\section{SUBJECTS AND METHODS}

Weather conditions of the area where research was conducted, are characterized by a moderately warm and humidified climate. Mean annual rainfall is about $374 \mathrm{~mm}$. Since April to October about $232 \mathrm{~mm}$ of rainfalls are dropped out. The sum of active temperatures in this area at the average by the years varies from 1950 to $2100{ }^{\circ} \mathrm{C}$, however, in the most particular favorable years this indicator increases to $2500{ }^{\circ} \mathrm{C}$.

At the beginning of May the average daily air temperature reaches about $9.3^{\circ} \mathrm{C}$, increasing up to $19.1{ }^{\circ} \mathrm{C}$ by June. In the middle of September this indicator decreases to $10.3{ }^{\circ} \mathrm{C}$. In the forest-steppe zone of the Trans-Ural region there are often frosts. According to the average long-term data the short spring frosts occur in the 2-3 decade of May, autumn frosts for the 2 nd decade of September.

The soil is a black earth heavily leached layer, shalow, argillaceous, and formed on carbon-bearing loessial loam. Morphological features and the main agrochemical and agrophysical properties are typical for such types of soils in the forest-steppe zone of the Trans-Ural region [11, 12].

The studies were conducted in 2016 and 2017 in the Tyumen region, Zavodoukovsky district, inside the territory of the agricultural enterprise CJSC "Centralnoye". The scheme of the experiment provided the use of various fertilizer rates. They were calculated by the method of an elementary balance using utilization coefficient from soil and fertilizers, and by the economic removal. The data received in Chelyabinsk region are presented in the table 1 . 
TABLE I. Doses of mineral fertilizers for obtaining the planned yield of corn, $\mathrm{kg} /$ ha of active substance

\begin{tabular}{|l|l|l|l|l|l|l|}
\hline \multirow{2}{*}{ Options } & \multicolumn{3}{|c|}{$\mathbf{2 0 1 6}$} & \multicolumn{1}{c|}{$\mathbf{2 0 1 7}$} \\
\cline { 2 - 7 } & \multicolumn{1}{|c|}{$\boldsymbol{P}$} & \multicolumn{1}{|c|}{$\boldsymbol{K}$} & \multicolumn{1}{|c|}{$\boldsymbol{N}$} & \multicolumn{1}{c|}{$\boldsymbol{K}$} \\
\hline Control & 0 & 0 & 0 & 0 & 0 & 0 \\
\hline NPK 4.0 t/ha & 80 & 60 & 60 & 60 & 60 & 60 \\
\hline NPK 5.0 t/ha & 110 & 80 & 80 & 80 & 100 & 100 \\
\hline NPK 6.0 t/ha & 150 & 100 & 100 & 120 & 120 & 120 \\
\hline
\end{tabular}

The experiment additionally included two sowing dates: the first date was in the second decade of May; the second date was in the third decade. We used ammophoska and ammonium nitrate as mineral fertilizers as they are the most widespread types of fertilizers for that region.

After cleaning the predecessor (oats) the soil was primarily cultivated by plows at the depth of $23-25 \mathrm{~cm}$. The soil with good tilth was harrowed in two traces - by the middle toothed harrow "BZSS,0". Mineral fertilizers were brought by the trailed seed fertilizer planter "SZP-3,6". Immediately following the fertilizers sinking the soil was cultivated by the steam speed cultivator "KPS-4". Seeds were sowed by the precision seed drill "SUPN-8A" with the seeding rate of 70 thousand plants per hectare. We sowed the hybrid "Obsky 140". The accounting of dry weight was carried out in 4-fold frequency, selecting 30 plants from each replication. At the period of harvesting we calculated biological yield of grain, and vegetative weight from 50 plants in 4-fold frequency on each replication. The grain was selected from ear corns and harvest humidity was defined by the thermostatic-weight method. We defined the humidity of vegetative weight and the dry weight by recalculation. The ear corns were threshed manually at achieving standard humidity and weighing each replication separately. Statistical data was processed by Dospekhov method with the use of Excel.

Before harvesting the corn biomass at the natural agrobackground was $14.4 \mathrm{t} / \mathrm{ha}$ of dry weight. In 2017 long cool summer in the first half of vegetation caused the increase of biomass by the end of vegetation by $14 \%$, than in 2016 (fig.1).

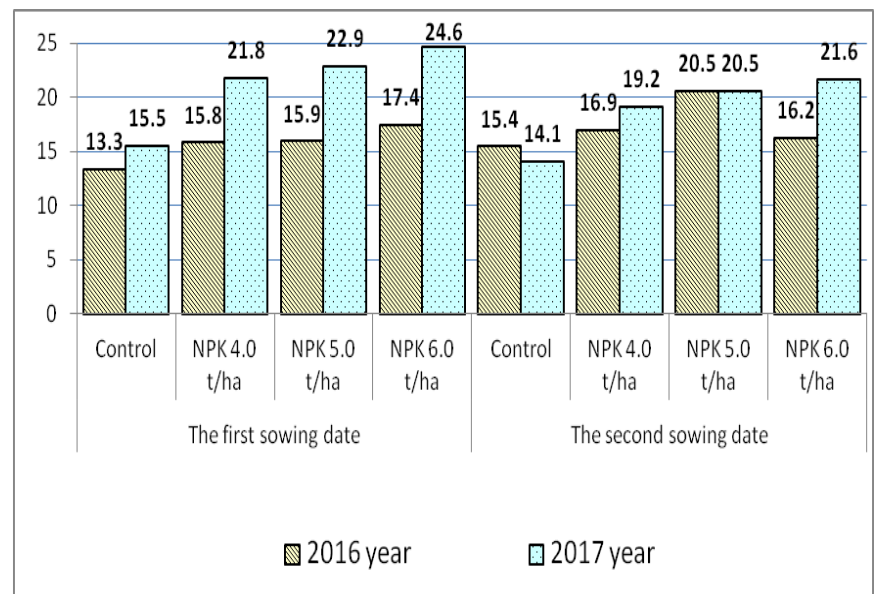

Fig. 1 - Influence of mineral fertilizers and sowing date on the dry weight of corn, $\mathrm{t} /$ hectare

The mineral fertilizers, introduced on the planned yield of $4.0 \mathrm{t} / \mathrm{ha}$ of corn kernels, promoted the increase in biomass averagely for two years by $23 \%$ relatively the option without use of fertilizers. It should be noted that in 2017 corn biomass was 6.0 tons higher, than in the previous year. Further increase in nutritional level on the planned yield of corn kernels $5.0 \mathrm{t} / \mathrm{ha}$ promoted the accumulation of $19.4 \mathrm{t} / \mathrm{ha}$ of dry weight on $5.0 \mathrm{t} / \mathrm{ha}$ more, than at the natural agrobackground. Further increase in mineral nutrition level has increased the accumulation of dry weight to $21.0 \mathrm{t} / \mathrm{ha}$ that is $31 \%$ more than control.

We supposed that corn seeding in the third decade of May had to provide the accelerated corn sprouting and provided the formation of heavy root system. However, according to the results of the research, the second date at the natural agrobackground had no distinctions with rather earlier seeding. The distinctions were not observed also on option with the planned yield of $4.0 \mathrm{t} / \mathrm{ha}$ of corn kernels. It should be noted that on the option with the planned yield of $5.0 \mathrm{t} / \mathrm{ha}$ of corn kernels at the second sowing date $1.1 \mathrm{t} / \mathrm{ha}$ of dry weight more was cumulated, than at the first date of seeding. We suppose that, it is connected with the disbalance of nitrogen and phosphorus in soil in 2016. That increased the vegetative period and additional vegetative weight. On the option where corns were fertilized $(6.0 \mathrm{t} / \mathrm{ha})$ averagely for two years there had been an insignificant decrease by $1.1 \mathrm{t} / \mathrm{ha}$ of dry weight in respect to the first sowing date.

The average yield of corn kernels on the natural agrobackground for research years has been 3.9 t/ha (fig. 2).

The mineral fertilizers introduced to the planned yield of $4.0 \mathrm{t} / \mathrm{ha}$ of corn kernels have provided an additional increase in 1.2 t., that is $24 \%$ more in respect to the control. Further increase in nutritional level on the planned yield of $5.0 \mathrm{t} / \mathrm{ha}$ of corn kernels averagely by years has provided the increase in harvest up to $5.3 \mathrm{t} / \mathrm{ha}$. Liberal application of mineral fertilizers on the planned yield of $6.0 \mathrm{t} / \mathrm{ha}$ of corn kernels allowed to succeeded averagely $5.8 \mathrm{t} / \mathrm{ha}$.

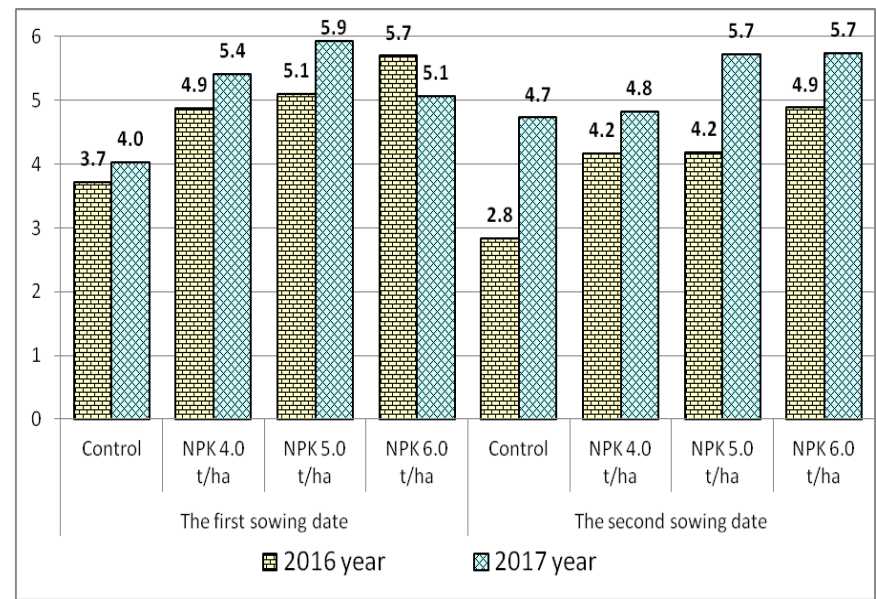

Fig. 2 - Influence mineral fertilizer and sowing time on yield of corn kernels , $\mathrm{t} /$ ha (in terms of standard humidity)

Shifting the sowing date to the third decade of May has led to decrease in yield of grain at the natural agrobackground by $0.6 \mathrm{t} / \mathrm{ha}$. Shifting sowing dates in the fertilized options has also led to decrease in yield of corn kernels by $12-20 \%$.

One of the limiting factors at growing corn kernel under such conditions is the harvesting humidity. The optimum humidity for harvesting corn kernels ranges from $20-30 \%$, the increase in humidity leads to losses as a result of corn squashing. According to our experiment, the harvest humidity of corn kernel on a natural agrobackground has been averagely $38.0 \%$ for two years. We should noticed that the harvest humidity of corn kernels in 2017 was slightly higher, than in 2016 because of the insufficient air 
temperature and a large amount of rainfall. Use of mineral fertilizers leads to the increase in this indicator. On option with the planned yield of $4.0 \mathrm{t} / \mathrm{ha}$ of corn kernels the humidity was $1.5 \%$ higher. When using the increasing doses of mineral fertilizers on the planned yield up to $6.0 \mathrm{t} / \mathrm{ha}$ the harvest humidity gradually increases, reaching $42.1 \%$. We revealed the high correlation $(0.76)$ between doses of nitrogen fertilizers and harvest humidity (fig.3).

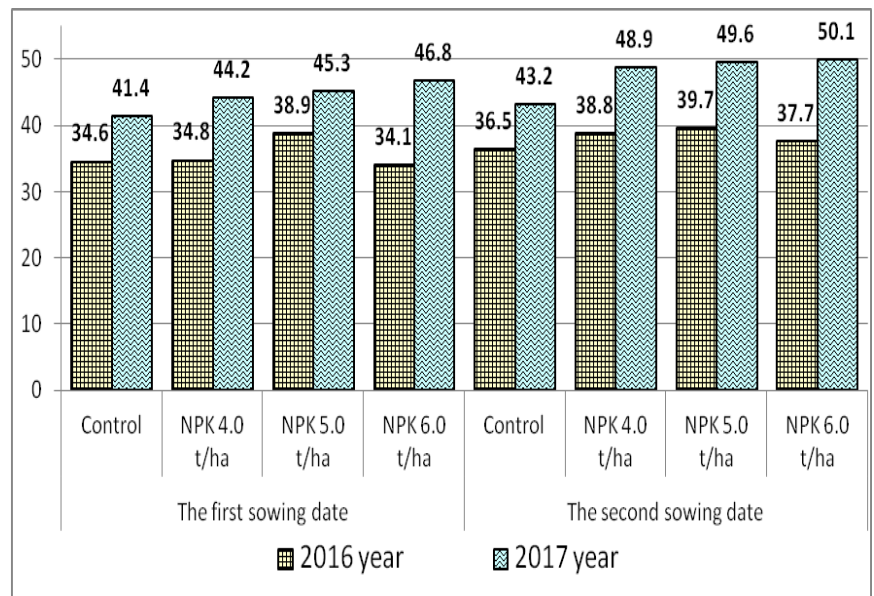

Fig. 3- Influence of mineral fertilizers and sowing time on harvest humidity of corn kernels , \%

At the second sowing date the yield of the harvest corn kernels humidity in the natural agrobackground has been $40.0 \%$ for years of research, and is $2.0 \%$ higher, than at the first date of sowing. The mineral fertilization of the planned yield up to $6.0 \mathrm{t} / \mathrm{ha}$ of corn kernels at the second date of seeding averagely for two years has promoted receiving the harvest with high humidity of grain $-44.7 \%$ that is $2.6 \%$ higher than the maximum humidity of grain at the first sowing date. The high harvest humidity of corn kernels in 2017 is connected with cold and rainy autumn which slows the maturing stage.

\section{CONCLUSION}

At seeding on May 15 the maturing of corn kernels was 132-137 days, mineral fertilizers slightly extended the interphase periods. Seeding crops in the second decade of May reduces vegetative stage for 6-7 days. At the first sowing date at the natural agrobackground the corn biomass was $14.4 \mathrm{t} / \mathrm{ha}$ of dry weight. Mineral fertilization promotes the increase of this indicator to $21.0 \mathrm{t} / \mathrm{ha}$ of dry weight. Seeding corn in the second date does not influence the accumulation of dry weight on options with mineral fertilizations on the planned yield up to $4.0 \mathrm{t} / \mathrm{ha}$ of corn kernels. Seeding corn in the first decade of May provided obtaining the planned yield on all options. Shifting of seeding time to the second decade of May leads to decrease in yield of kernels by $0.3-0.6 \mathrm{t} / \mathrm{ha}$ relatively the first sowing date. The humidity of corn kernels at the first seeding on May 15 on control was $38.0 \%$, mineral fertilization promoted increase in this indicator by $1.5-4.1 \%$, in regards to control. At the second date of seeding the harvest humidity of corn kernels was $1.8-4.4 \%$ higher in regards to the first sowing date.

\section{References}

[1] S.I. Kononenko, I.S. Kononenko, "Replacement of corn with grain of a sorghum in compound feeds for broilers", News of Mountain state agricultural university, 2011, vol. 2, pp. 71-73

[2] V.V. Koshlyaev, "Formation of grain efficiency of early ripe hybrids of corn in the conditions of Central Volga area", Agricultural biology, 2003, vol. 3, pp.78-84

[3] M.A. Chasovshchikova, O.M. Sheveleva, M.A. Svjazhenina, N.I Tatarkina, A.V. Satkeeva, A.A. Bakharev, E.A. Ponomareva and A.G. Koshchaev, "Relationship between the genetic variants of kappa-casein and prolactin and the productive-biological characteristics of cows of the black-motley breed", Journal of Pharmaceutical Sciences and Research, vol. 9, 2017, pp. 1038-1044.

[4] A.I. Kassamedinov, R.G. Razumovskaya, "Increase in nutritional value of the forages applied in poultry farming", Bulletin of the Astrakhan state technical university, 2008, vol. 3, pp. 110-114

[5] S.F. Sukhanova, A.G. Makhalov, O.A. Nevzorov, "Increase in efficiency of indicators of geese of the Italian white breed divorced in the conditions of the Trans-Ural region", Siberian messenger of agricultural science, 2007, vol. 3, pp. 42-47.

[6] A. Lyubimova, D. Eremin, "Laboratory varietal control as a guarantee of successful work of gribusiness in Russia," [MATEC Web of Conferences, no. 170, 2018, pp. 04015]. https://doi.org/10.1051/matecconf/201817004015

[7] V. Sapega, G. Tursumbekova, "Yielding ability and adaptability parameters of cereal crop varieties in the forest steppe of Northern Transuralia", Russ. Agric. Sci., vol. 36, 2010, pp. 160-165, 10.3103/S1068367410030031

[8] Y.P. Loginov, A.A. Kazak, L.I. Yakubyshina, T.N. Falaleeva, S.N. Yashchenko and E.T. Yarova, "Breeding value of collection varieties of potato in the forest-steppe zone of the Tyumen region", Journal of Pharmaceutical Sciences and Research, vol. 1, 2018, pp. 377-380.

[9] A.S. Lukatkin, N.N. Grishenkova, L.P. Martynova, "To a question of acclimation of sprouts of corn to the lowered positive temperature of cultivation", Agricultural biology, 2006, No. 1, pp. 86-91.

[10] D.I. Eremin, "The dynamics of agrophysical properties of the arable chernozem under the effect of many years use of mineral fertilizers in the forest-steppe zone of Zauralye", Agrophysics, vol. 2, 2018, pp. 914. DOI: $10.25695 /$ ARPH.2018.02.02

[11] D.I. Eremin, "Changes in the content and quality of humus in leached chernozems of the Trans-Ural forest-steppe zone under the impact of their agricultural use", Eurasian soil science, 2016, vol. 49, No 5, pp. 538-545. DOI: $10.1134 / \mathrm{S} 1064229316050033$

[12] D. Eremina, "The impact of transport infrastructure on ecological status of arable land in Western Siberia", [MATEC Web of Conferences, no. 170, 2018, pp. 05004]. https://doi.org/10.1051/matecconf/201817005004

[13] S. Khanal, J. Fulton, N. Douridas, "Integrating aerial images for inseason nitrogen management in a corn field", Computers and Electronics in Agriculture, No. 148, 2018, pp. 121-131.

[14] Z. Jin, R. Prasad, J. Shriver, Q. Zhuang, "Crop model- and satellite imagery-based recommendation tool for variable rate $\mathrm{N}$ fertilizer application for the US Corn system", Precision Agriculture, 2018, No 18(5), pp. 779-800.

[15] G. Cambareri, C. Drury, J. Lauzon, W. Salas, C. Wagner-Riddle, "Year-Round Nitrous Oxide Emissions as Affected by Timing and Method of Dairy Manure Application to Corn", Soil Science Society of America Journal, 2018, vol. 81(1), pp. 166-178.

[16] J.R. Russell, W.J. Sexten, M.S. Kerley, "Effect of corn inclusion on soybean hull-based diet digestibility and growth performance in continuous culture fermenters and beef cattle", Journal of Animal Science, 2016, vol. 94(7), pp. 2919-2926.

[17] G.C. Sigua, K.C. Stone, P.J. Bauer, A.A. Szogi, "Phosphorus dynamics and phosphatase activity of soils under corn production with supplemental irrigation in humid coastal plain region", USA, Nutrient Cycling in Agroecosystems, 2017, vol 109(3), pp. 249-267.

[18] A. Sadeghpour, Q.M. Ketterings, G.S. Godwin, K.J. Czymmek, F. Vermeylen, "Agro-environmental consequences of shifting from nitrogen- to phosphorus-based manure management of corn", Soil Science Society of America Journal, 2017, vol. 81(5), pp. 1127-1138.

[19] Z Tan, S Liu, Soil nutrient budgets following projected corn stover harvest for biofuel production in the conterminous United States, GCB Bioenergy, 2015, vol. 7(2), pp. 175-183. 